there followed the main lines laid down by his predecessor. The programme consisted of three parts : the parallax work, the determination of positions and proper motions of stars in the Cape astrographical zones, and the compilation of a "Photographic Zone Catalogue" for the region $-30^{\circ}$ to $-90^{\circ}$ in declination. Spencer Jones's programme, inaugurated in 1926, was the measurement of the parallaxes of all possible stars of proper motion exceeding $40^{\prime \prime}$ a century south of declination $-10^{\circ}$. Although a number of determinations had been made when Jackson assumed office, the greater part of the programme remained to be executed, and results were published from time to time in the Monthly Notices and in three successive volumes of the Cape Annals, which were edited by Jackson. In his annual report for 1949 Jackson announced that 1,623 parallaxes had been determined since the work started and that it was then almost completed. The results of the second part of the programme were published in 1936 under the titles "Proper Motions of Stars in the Zone Catalogue of 20,843 Stars, 1900, Zones $-40^{\circ}$ to $-52^{\circ}$, derived from the Photographs taken at the Royal Observatory, Cape of Good Hope", and in 1939 in "Catalogue of 20,554 Faint Stars in the Cape Astrographic Zone $-40^{\circ}$ to $-52^{\circ}$, for the Equinox of $1900 \cdot 0$, giving Positions, Precessions, Proper Motions and Photographic Magnitudes, derived from Photographs taken at the Royal Observatory, Cape of Good Hope". Many important statistical results were derived from this study of more than forty thousand southern stars, and the information obtained has an important significance for the future. Good progress has also been made on the third part of the programme, the compilation of a "Photographic Zone Catalogue". for the region - $30^{\circ}$ to $-60^{\circ}$ in declination, with the wide-angle cameras, in which programme magnitudes and colours have also been included.

Prof. Dingle referred also in his address to a number of other tasks which Dr. Jackson has undertaken at the Cape; but it is sufficient in this résumé to quote Prof. Dingle's words that "The Gold Medal of our Society is bestowed for outstanding excellence of astronomical work, and for nothing else".

\section{BRITISH DEPENDENCIES IN THE CARIBBEAN AND NORTH ATLANTIC}

$\mathrm{P}$

ROF. W. M. MACMILLAN'S "Warning from the West Indies" was published in 1936: the 'warning' of the book's title, he wrote later, was "originally an appeal, and looked to the future". How far his warnings and those of others have been heeded may be judged by a recently issued Colonial Office publication* which surveys the history of the British territories in the Caribbean and North Atlantic during the past thirteen years. It is the fourth in a series of official reports designed to take a longer view of trends and developments than is possible in the various annual Colonial reports. The previous reports have covered the post-war period in the Far East (Cmd. 7709, 1949), East and Central Africa (Cmd. 7987, 1950), and the British islands in *Colonial Office. "British Dependencies in the Caribbean and
North Atlantic, 1939-1952." (Cmd. 8575.) $\mathrm{Pp}$. xi +98 . (London: H.M.S.O., 1952.) 38, 6d. net. the southern hemisphere (Cmd. 8230, 1951). The present report extends its range backwards to 1939 and even earlier, and it does so wisely, for the situation to-day in these areas is so dependent on the circumstances of the inter-war and war years that it is impossible to understand it without reference to this background.

This point is clearly made in the first chapter of the report, "The Seeds of the Present", which summarizes the position in the period preceding the appointment of the West Indies Royal Commission of 1938-39 and the results of that Commission, and reviews the events of the war-years that followed. The Commission decided that the region was in urgent need of social services which it could not afford from its own resources or from any unassisted development of these resources that was likely in the near future. Considerations such as these in the Colonial Empire generally lay behind the establishment of the Colonial Development and Welfare Fund in 1940: in the West Indies a Development and Welfare Organization was set up with the late Sir Frank Stockdale as its first comptroller and, despite war-time shortages, much re-organization and rehabilitation were carried through. Although, as the report puts it, "the impact of the war was manifold and serious", the end of the War left the West Indies with their basic economy largely intact and with good prospects for the planning of the future.

The chapters that follow and the useful statistical appendixes present a synoptic view of the situation to-day. The survey of political and constitutional development indicates the diversity of political structure and the complexity of local government, as well as the variety of ways in which advance is being made in the different territories from representative to responsible government. It also explains both the difficulties and the prospects of federation, towards which there is a distinct movement in most of the islands and about which a further conference is to be held in London in April.

The economic outlook just before the Second World War was, to quote the Royal Commission, "not at all reassuring", on account of the depression in the main primary-producing occupations of the region and because of the problems resulting from the high natural rate of increase of population. To-day the report states that "the uncertainty of the inter-war years has gone", partly through the development of new markets and of systems of guaranteed prices, and partly because of action taken under the Development and Welfare Acts to strengthen the region's economy, particularly its agriculture. At the same time, some of the economic problems have been intensified: developments in preventive medicine, in particular, by increasing the rate of growth of population, are already increasing the demand for education and for employment. The necessity for "the more intensive use of the land with increased production of food" is as great to-day as when the Royal Commission expressed this need, and it is satisfactory to learn that since 1939 there has emerged a new approach to the question of the most efficient use of the land, for foodstuffs as well as for export crops such as sugar, cocoa and bananas. There has been progress, too, in animal husbandry, forestry, the processing and other industries, and mining (British Guiana is the world's second largest producer of bauxite, which is also now being mined in Jamaica with the financial assistance of the Economic Co-operation Administration of the United 
States). Despite these and other developments, unemployment and under-employment remain serious problems, though good progress has been made in the fields of labour supervision and industrial relations.

The general emphasis of the Royal Commission's recommendations was on welfare rather than on development, and it is not surprising to find much more advance in the social services than in economic productivity. The links between the two have been discussed in Britain in recent years, and for the Caribbean were considered by Prof. T. S. Simey (one of the war-time advisers to the Comptroller for Development and Welfare) in his "Welfare and Planning in the West Indies" (1946). Although the report notes that "in recent years it has been increasingly recognised that the maintenance of improved social services calls for intensive and sustained efforts to promote economic development", it very rightly emphasizes the considerable progress made in education, medical services, and social welfare generally.

In the modern world no area can be understood in isolation from its neighbours, least of all these British islands for which, as the report states, "a co-operative policy has been a firm feature of the conduct of affairs". International relations with the United Nations, the United States, Guatemala and Venezuela are discussed, and special attention is given to the significance of the Four-Power Caribbean Commission, which is to concentrate in future less on overall research (much of which has been done) than on those activities that have direct bearing on immediate economic development-agriculture, forestry, fisheries, industrial development and housing, in that order. Reference is also made to the considerable numbers of West Indians working and studying overseas, and to their importance in the two-way process of West Indians knowing the world and being known to the world.

The Colonial Office has produced in this report a very readable, well-balanced and most valuable account of these territories and their peoples. A realistic assessment has been made of the prospects of political, economic and social development, and some at least of the probable limitations on such progress are stressed. The main interest in the period under review has lain not in the discovery of now problems but in the progress made in dealing with them, and in the increasing recognition of the importance of joint action as a means of meeting the economic and other problems of the region. "Increased productivity, as a basis for improved or even maintained standards of living, remains the fundamental need," the report concludes, "and this must be the main objective of Governments and peoples alike in the years to come." Up to a point, this survey has covered the area's problems in a comprehensive and understanding manner : yet nowhere is there any real or sustained analysis of the problems posed by the rapid growth of population in nearly all these dependencies. To-day they have some $3,200,000$ people; within a generation it seems there may be five or even six million. If this is so, is not increase of population the major problem of these British territories? Are the individual governments and the Colonial Office really alive to the urgency of this aspect of the future of the Caribbean territories ? They probably are, but this report will scarcely give the informed reader that impression.

R. W. STEEL

\section{HUMIDITY OF THE UPPER TROPOSPHERE AND LOWER STRATOSPHERE}

$T$

HE troposphere is the lower part of the atmosphere, and the stratosphere the upper part. Temperature in the troposphere on the whole falls with height at the rate of about $3^{\circ} \mathrm{F}$. per $1,000 \mathrm{ft}$.; but in the lower part of the stratosphere it changes little with height. The troposphere and stratosphere are separated by the tropopause, a shallow layer within which the vertical temperature gradient changes rapidly. Over southern England the mean height of the tropopause is about $37,000 \mathrm{ft}$. in summer and $35,000 \mathrm{ft}$. in winter, but large variations, sometimes exceeding $10,000 \mathrm{ft}$., occur on either side of the mean. The tropopause is low over depressions and high over anticyclones.

Within the troposphere there is much mixing of air by convection currents, and this convectional stirring produces the large fall of temperature with height. The temperature distribution in the lower stratosphere is believed to be determined by radiative equilibrium in which water vapour, as the most important constituent of the atmosphere absorbing and emitting long-wave radiation, plays a predominant part. Knowledge of the water vapour content of the upper troposphere and lower stratosphere is therefore important for study of the radiative exchange of heat in the atmosphere. It is also important in connexion with both large-scale and small-scale atmospheric circulations because, provided there is no condensation of water vapour, the ratio of mass of water vapour to mass of air (the humidity mixing ratio) remains constant as the air moves. Another application is to the formation of condensation trails which are important in military aviation.

The temperature at tropopause-level is very low, rarely exceeding $-50^{\circ} \mathrm{F}$. $\left(-45 \cdot 6^{\circ} \mathrm{C}\right.$. $)$ and being often below $-80^{\circ}$ F. $\left(-62 \cdot 2^{\circ}\right.$ C.). This makes humidity measurements difficult, because instruments such as hair hygrometers are extremely sluggish at such low temperatures. The problem of measuring humidity at this level was solved in 1942-43 with the invention by Prof. G. M. B. Dobson and Dr. A. W. Brewer of a frost-point hygrometer operating on the same principle as Regnault's dew-point hygrometer. The instrument can be carried in an aircraft; with it the first observations of humidity in the lower stratosphere have been made, and a detailed analysis of the observations taken with the instrument in the course of 130 flights between 1943 and 1950 over southern England has been published in Geophysical Memoirs No. 88 of the Meteorological Office*.

The most striking feature is the extreme dryness of the lower stratosphere. This was quite unexpected. The mean relative humidity with respect to ice at the tropopause is 41.5 per cent, but at a height of about $6,000 \mathrm{ft}$. above (more precisely at $50 \mathrm{mb}$. lower pressure) the mean is only 5 per cent. The frost point in the lower stratosphere is rarely outside the range $-80^{\circ}$ F. to $-120^{\circ}$ F. $\left(-62 \cdot 2^{\circ}\right.$ C. to $-84 \cdot 4^{\circ}$ C. $)$. The corresponding saturation vapour pressures are $7.8 \times 10^{-3} \mathrm{mb}$. and $2.6 \times 10^{-4} \mathrm{mb}$.

* Air Ministry : Meteorological Office. Geophysical Memoirs No. 88: Humidity of the Upper Troposphere and Lower Stratospher over Southern England. (M.O. 530c.) By J. K. Bannon, R. Frith and H. C. Shellard. Pp. 36. (London: H.M.S.O., 1952.) 28. $6 d$. net. 